\title{
Trade Facilitation-Measurement Difficulties in the Computable General Equilibrium Model: A Review
}

\author{
Subashini Perera*, Mahinda Siriwardana, Stuart Mounter \\ UNE Business School, University of New England, Armidale, Australia \\ Email: *aperera4@myune.edu.au
}

How to cite this paper: Perera, S., Siriwardana, M. and Mounter, S. (2017) Trade Facilitation-Measurement Difficulties in the Computable General Equilibrium Model: A Review. Theoretical Economics Letters, 7, 154-163.

https://doi.org/10.4236/tel.2017.72013

Received: November 10, 2016

Accepted: February 1, 2017

Published: February 4, 2017

Copyright $\odot 2017$ by authors and Scientific Research Publishing Inc. This work is licensed under the Creative Commons Attribution International License (CC BY 4.0).

http://creativecommons.org/licenses/by/4.0/

c) (†) Open Access

\begin{abstract}
This paper reviews research on quantitative assessments of the economic impacts of Trade Facilitation (TF), based on Computable General Equilibrium (CGE) models, in the context of techniques adopted to estimate Trade Transaction Costs (TTCs). Insufficient TF poses a barrier to trade and is a major concern of the second generation trade policy agenda. Thus, recent CGE applications such as GTAP are generally associated with estimations of the benefits of eliminating TTCs by TF improvements, in that impacts of these trade barriers surpass those of tariff barriers, particularly in developing countries. However, accessing data relating to TTCs are limited, as no standard database has yet been developed. Thus, outcomes of existing CGE models vary in terms of the approach selected for TTC estimations. This paper outlines the methodological approaches adopted in recent research for estimating TTCs to incorporate into TF-related CGE models. Our literature survey revealed that two methods have been employed incorporating TTCs into CGE models and both approaches produced variances in estimating shortfalls. This review identifies the importance of developing a standard up to date trade costs database, including investment spending of TF implementations, which can be incorporated into GTAP aggregation to model TF variables, since cost benefit assessment is integral to determining the net global benefits of TF. Future TF related research should prioritise this process, since this is crucial for assessing the accurate economic impacts of eliminating TTC especially in developing countries.
\end{abstract}

\section{Keywords}

Trade Facilitation, Trade Transaction Costs, Computable General Equilibrium, Ad Valorem Equivalents 


\section{Introduction}

Quantitative estimations of the benefits of Trade Facilitation (TF) initiatives are complex. The term TF has been applied to the economic effects of transporting or translocating goods and services across borders (narrow focus) and/or along the entire supply chain (wider focus). Hence, a definition of TF is dependent on the extent of measures incorporated [1] while the process of quantifying resultant economic benefits varies in complexity, relative to the inherent set of measures.

Insufficient TF poses a barrier to trade, increasing Trade Transaction Costs (TTCs). Improving TF minimizes TTCs in terms of the trans-border movements of imports and exports. Certain TTCs are transparent and data are available for estimating their economic impact. However, TF complications arising predominantly through trade delays and related indirect (time) costs are less demonstrable and more difficult to measure in monetary terms.

Despite the difficulties associated with measuring the economic impacts of TF, there have been numerous empirical studies which have attempted to estimate the impact of TF on global economic development. There are two dominant methods applied by trade economists to measure the impacts of TF: Partial Equilibrium methods (Gravity models) and Computable General Equilibrium (CGE) modeling.

Studies related to the gravity model are generally abundant in the literature since the model is not data intensive. This model only requires trade flows as dependent variables and the factors related to TTCs that could be lowered through efficient TF measures as independent variables. Thus, it requires only trade data and some proxies for TTCs. The results show a number of correlations. However, Hummels, Minor, Reisman and Endean [2] have argued that assessment of TF based on the gravity model has two inherent weaknesses. Firstly, the equation assumes a causal relationship between TTC variables and trade, which omits differentiation of particular trade costs. Secondly, gravity equations link trade volumes with other variables such as border waiting time, but do not estimate these delays in monetary terms. Hence, gravity model outcomes only partially outline the relationship between trade flows and TTC related factors. Reliability of model outcomes is dependent on model selection, data and interpretation of parameters [3]. Further, the outcomes of the gravity model are limited in the ability to account for real resource restrictions such as land, labor and capital. Nor does the model define sectoral linkages, since no specific economic accounting scheme is imposed [4].

However, TF can affect trade flows (exports and imports) and hence production, factors of production and remuneration, government revenue and welfare impacts across the entire economy. The benefits of TF permeate the entire economy and, thus, assessing these impacts in a general equilibrium closure is imperative. The CGE modeling framework is better suited to assess the full extent of TF impacts, since it can explain the economy wide interactions [5] [6]. However, there is no TF related data available in CGE modeling databases for 
assessing TF economic impacts. Therefore, researchers estimate the costs of TF as tariff equivalents, based on econometric methods or sets of assumptions, in order to include these costs into the model database. After developing the baseline including the TF variables, CGE modelers can simulate different TF scenarios to determine the economic impacts of TF on both developed and developing countries, within the boundaries of estimation shortfalls. However, with no standard mechanisms to assess TF economic impacts within the CGE model, the TF related studies vary widely, depending on the method with which TTCs have been estimated and incorporated into the model.

This paper seeks to identify the importance of developing an updated TTC database which can be used as a supplementary input to the main databases in order to implement TF within the CGE framework. There is a paucity of research summarizing the recent literature related to estimating TTCs. This paper reviews and critiques TF related CGE studies, focusing on the techniques employed to estimate TTCs and the methodological approaches used to assess the economic impacts within the CGE framework, as well as highlighting future research needs. The elements of TTC are discussed briefly in Section 2 of this paper. The estimations of TTC and their implementation in CGE models is reviewed in Section 3 in order to highlight the limitations of existing TF related CGE studies. The conclusions of this paper, together with comments and suggestions regarding future research, are provided in Section 4 .

\section{Elements of Trade Transaction Costs}

There are numerous reasons why TTC can arise at border crossings. According to OECD [7], TTC related to border procedures varies depending on the efficiency and integrity of interacting businesses and administrations, type of goods and the size and type of business. For example agro-based commodities that are perishable by nature need quicker delivery times. However, such goods are highly subject to documentary and physical inspections and other procedures at the border. This significantly increases the border process fees and clearance times. Shepherd [8] details the circumstances whereby TTCs arise, including those that may be referred to as "natural" in the sense that they reflect inherent factors such as geographical distance or linguistic and cultural differences. In this sense, the total TTC is composed of both direct and indirect costs.

Direct TTC are the charges that are directly applied to trade transactions. This type of direct border transit cost includes customs clearance fees, charges of logistic services, and costs of providing necessary documentation. The direct costs are obvious and measurable in dollar terms. Improved TF lowers this type of cost by harmonizing and simplifying customs procedures.

Indirect TTC arises due to procedural delays at the borders. However, it is very difficult to express these in monetary terms since such costs are difficult to observe or tabulate. For example, Hummels [3] explains that delays in transactions may necessitate additional inventory holding costs for traders in order for them to maintain buffer stocks to avoid inconsistent border clearance times. 
Hummels [3] further states that inventory costs include both capital costs of the goods while they are in transit and costs of holding larger inventories to accommodate variation in arrival time. The latter has become increasingly important due to the use of "just in time" production techniques. The delays in border transactions may even cause traders to lose business opportunities because quick delivery is such an important element of the modern global business environment. This is most serious for those businesses trading fresh products, items with immediate information content such as newspapers, and goods for which demand cannot be forecasted well in advance, such as highly season-sensitive fashion apparel or seasonal holiday toys [7]. The most obvious fresh products are agricultural and horticultural products that physically deteriorate with the passage of time. However, timely trade is also crucial for many technological products as consumers place a high value on purchasing the latest innovations [4]. Therefore, time is becoming the most important factor in determining business competitiveness.

The empirical literature strongly points to the time consumed when goods and services are crossing borders for export or import as being a key element when addressing TTC. Hummels [3] highlights that time savings can have immense benefits for international trade. Persson [9] also argues that border delays are a good proxy for the TTC that TF aims to lower. Djankov, Freund and Pham [10] further show that the impact of long time delays on trade is comparable to that of a tax on exports or imports due to depreciation of goods, resources being allocated to storage and transport instead of other uses, and/or increased uncertainty about delivery times.

\section{Estimation of Trade Transaction Costs and Implementation in Computable General Equilibrium Models}

There are two types of global CGE model which have been used to assess the benefits of TF, the Global Trade Analysis Project (GTAP) model and Multiregional and Multi-sectoral (MIRAGE) CGE model. The two differ in their approaches to modeling TF within the CGE framework. The iceberg method has been most commonly applied to TF within the GTAP model, whereby TTCs are introduced as a technical shift in the Armington import demand function. Thus, TTCs are treated as changes in the unobserved technical coefficient of AMS in the import demand function. However, Walmsley and Minor [11] have recently argued that the iceberg approach tends to overestimate the impacts of TF, and instead propose the "willingness to pay" method, which has not yet been empirically tested by other CGE modelers. Conversely in the MIRAGE model, TF is incorporated in the price and transport equations [12] [13].

The majority of TF related CGE studies are based on the GTAP database and associated models, which may be classified as either static or dynamic. The standard GTAP model is a static model which does not account for long term growth effects. This limitation has led to the popularity of the GTAP dynamic model as it facilitates the inclusion of variables such as capital accumulation, 
population growth, labor supply and technological development. Whether static or dynamic, TF related GTAP models can be categorized as bi-lateral, regional or multilateral-global models.

TTC related data is not available in the standard GTAP database and hence, the introduction of TTCs into a GTAP model presents challenges. Studies of TF which have used the GTAP database as the main input display a variety of approaches to the estimation of TTC impacts on the import demand function. Most common has been the introduction of trade delays (time costs) as a proxy variable of TTCs, in that trade delays due to poor TF impact adversely on trade volumes. Time taken in moving goods to the market affects trade flows in two ways. Firstly, it determines whether or not firms will enter a particular foreign market. Secondly, once a market entry is made, time affects the volume of trade [14]. Faster transactions are critical for enhancing bi-lateral trade flows. However, analysis and estimation of the value of time is difficult due to the complexity and interdependencies of its impacts.

For this reason, some CGE modelers have included supplementary data as a proxy for the costs of trade delays, based on assessment of the validity of a casespecific set of assumptions. For example: OECD [7] used the GTAP framework to assess the impacts of TF on developed and developing countries, assuming that the costs of trade delays are higher for agro-food products compared to manufactured products, and that small and medium enterprises incur higher time costs than larger enterprises. However, according to Hummels et al. [2] this assumption is inconsistent through the sector, as trade delay costs of specific products such as dried grains and other bulk products are less than those of fresh products. Similarly, specific manufactured products costs such as clothing and electronic items also incurred relatively higher time costs than the mean for the sector. Hummels et al. [2] substantiated such sectoral inconsistencies showing that some manufactured products suffer rapid depreciation in market value as a result of extended time delays. They further showed that costs of lengthy delays of intermediate goods accumulate throughout the value chain, with the final product reflecting the greatest sensitivity to delays. Thus, broad assumptions in estimating impacts and costs of trade delays across a supply chain may reduce the accuracy of results.

Some studies have attempted to estimate the impacts and costs of trade delays as Ad Valorem Equivalents (AVEs) of imports and exports [2] [3] [15]. AVEs of time to trade indirectly measure the effects of improved $\mathrm{TF}$ as factors reflected in price changes. The price effect of TF is the difference between the market price and the hypothetical price resulting from improved TF measures. The AVEs form a percentage of the total value of the traded good. This method has practical value in capturing the aggregated effects of all TF measures where individual influencing factors cannot be extricated [1]. Important principles relating to the estimation of AVEs of time in trade are covered in the above studies. Firstly, such data types assist researchers in the execution and development of quantitative TF impact analyses, similar to analyses of conventional tariff effects. Se- 
condly, these AVE results enable policy makers to identify efficient measures to improve TF in countries or trade sectors with higher trade costs and time sensitive products, whereby exports may be threatened.

Hummels et al. [2] and Hummels and Schaur calculated AVEs of trade time for 1000 traded commodities across 175 countries [15], as a modification to his paper [3]. The results confirmed that goods subject to rapid depreciation are time sensitive (fresh agricultural commodities and some manufactured products) while bulk products such as crude oil exhibit no such time sensitivity. Further, it was confirmed that AVEs for delays exceeded normal tariffs in every region. This approach for estimating AVEs for delays during the transaction refines the process of capturing indirect TTCs, enhancing the accuracy of evaluating TF impacts. Many later studies have tested the impact of trade delays based on AVE data.

Hertel, Walmsley and Itakura [16] used estimations of AVEs of time to trade in Hummels [3] to model TF components, using the iceberg approach in a GTAP model to assess the Japan-Singapore Free Trade Agreement (FTA). Their assessment estimated the average value of a firm's willingness to pay for one day saved in trade as 0.5 percent ad valorem. In considering the value for time savings in specific product categories, bulk commodities were assigned lower values and intermediate goods highest value. The results of this dynamic GTAP model highlighted the importance of TF components in enhancing trade under the FTA. However, the implementation costs of TF improvements are enormous and possibly prohibitive for developing countries. Thus, cost-benefit analysis of TF implementation programs to enhance faster delivery of goods and services is vital, while capturing these costs in a macroeconomic model such as GTAP is important for greater accuracy of results and guarding against overestimations. However, Hertel et al. [16] rated the implementation costs of TF improvements as small in relation to the potential benefits of this particular FTA.

The macroeconomic impacts of poor TF may, in specific cases, comprise both trade delays and unnecessary service charges arising from inefficiencies along the supply chain. Examples of inefficiencies include payments by traders for non-essential or uncompetitive border crossing services and the time involved in the multiple steps of specific border crossing operations [5]. In such case studies, time costs can be modeled by the iceberg approach with AVEs and direct charges incorporated into the GTAP model, following the approach applied in modeling normal import tariffs [5] [6] [7] [17]. These studies concluded that a reduction in indirect TTCs results in greater welfare gains, in comparison with a reduction in direct TTCs. However, if the treatment of eliminating unnecessary service charges is considered as a complete deadweight loss, there would be a party who is worse off due to eliminating the revenue gain from these charges [5]. Thus, a complete analysis of transaction flows related to TTCs is paramount.

In recognizing the importance of AVEs of trade delays in modeling the impacts of TF for the baseline in the GTAP model, Minor and Hummels [18] constructed a new AVE of time to trade database. This is a supplementary database 
to the existing GTAP database based on the estimations of Hummels et al. [2]. The supplementary database aggregates time to trade for each product and country, based on the existing GTAP database (version 8.1) which includes 134 countries and 57 sectors. The aggregated time values were estimated using US trade and transport data. Hence, the application of the database to TF modeling within the GTAP model may have limitations in the case of developing countries.

In general, the AVEs of trade delays database is a useful adjunct to the GTAP model, as the data enhances simulations of reductions in time cost as a measure of TF improvements. This enables modelers to capture the overall effects of trade delays as a component of changes in prices of traded goods. However, a limitation of this approach is the lack of identification of individual TF elements that lead to increased time delays. Consequently detailed information is not provided on specific TF areas of improvement that countries should consider.

The impact on TF of specific influential variables differs according to the size and nature of the economy and the rules and regulations imposed by particular trading partners. Thus, an analysis of the TF components that explicitly affect the impact of TF on trade provides the basis for implementing TF improvement policies in developing countries. This may include measuring customs inefficiencies in terms of number of days and documents necessary to fulfil the export and import processes, availability of online document submission facilities, transportation infrastructure and the geophysical aspects of the country and its borders, such as being landlocked or an island. These factors can be used to identify how countries facilitate exchanges in trade and the impact on international trade. Poor infrastructure may retard the development of both exports and imports and limit international trade growth [19] [20] [21] [22] [23]. In gravity model-based studies, infrastructure is a quantitative element in determining TF. Poor institutional quality and underdeveloped infrastructure limit trade in developing countries, as well as market access for exports from developed countries. Behar, Nelson and Manners [24] found that improving trade logistics, significantly reduced TTCs, while Fink, Mattoo and Neagu [25] highlighted the relative importance of communication costs, in comparison with other trade cost components.

AVEs of TTC data processed in gravity models can be used to model TF in a CGE framework. Initially, TTC parameters are estimated based on correlations between trade flows and TF variables derived by the gravity model. These estimated parameters are then used to develop a TTC database for different sectors and regions within the CGE multi-regional framework. This database provides CGE modelers with a supplementary input tool for their simulations. Zaki [13] used the process to measure the costs of red tape (administrative and bureaucratic barriers) and the resultant impact on world trade. He assessed the impact of TF in developing and developed countries based on AVEs of administrative barriers to trade at a global level, using a modified version of the MIRAGE model. Two-step estimation was performed to obtain red tape AVE values. Firstly, time 
to export and import were regressed, using as determinants the numbers of documents demanded to export or import and procedures required to start a business, levels of internet coverage and corruption and ease of geographical access, in order to capture the institutional environment. These variables were used as proxies for administrative barriers. Secondly, the predicted values of time to export and import obtained from the first step were integrated into the gravity model and the outcome was used to compute AVE values. According to Zaki [13], estimating AVEs of various TF variables, in addition to the time variable, enables researchers to capture the complexities of TF processes. The end results of the completed process facilitate a detailed understanding of the phenomenon of TF and its wide-ranging economic implications. Zaki, however, emphasized that his estimations were measures of gross gains, since he was unable to capture precisely the implementation costs of $\mathrm{TF}$, as data reflecting such costs at the global level, were unobtainable.

\section{Conclusion and Research Needs}

The outcomes of existing GTAP applications vary widely in terms of reference year of the study, TF components considered, sample-size of countries, in addition to choice of estimation approach in TTC and TF modeling. The empirical results of these studies have not been discussed, in that the primary purpose of our research was to assess limitations in the estimation of, and modeling approaches to, TF variables within the CGE model. Our review has not focused on the evolution of TF related CGE studies, but rather on highlighting selected papers that have contributed significantly to the development of the related literature. Further, our review does reveal significant gaps related to the estimations of TTC and implementation of TF in the CGE modeling framework. The two basic approaches employed to estimate TTCs were reviewed, considering that no specific TF data exist in the standard GTAP model. One approach to estimating AVEs of trade delays assumes that the effect of trade delays exceeds other direct charges. This approach is based on the demand function, derived from commodity specific estimates of the willingness of consumers and producers to pay to avoid time delays. However, developing this type of database is complex, costly and time consuming. Further, the existing database is based on US trade and transportation data and the validity and accuracy of applying generalized AVEs to other economies and regions is questionable. AVEs of time to trade data provide a limited method for the analysis of TF components, and thus some compromise in the accuracy of outcomes. The alternative approach estimates parameters of specific TF components to fit the gravity model, thereafter incorporating these into the CGE model. This approach has greater value for analyzing the impact of TF in terms of special policy implementation programs, particularly in developing countries, since it enables modelers to argue which TF components need prioritization in a specific economy. Our research noted the minimal interest in developing a standard trade costs database, as a supplementary input to the main GTAP updated data base. A TF database is yet to be con- 
sidered. Another important finding of our review is that incorporating the aggregated costs to the economy of TF implementation into the CGE model has not yet been investigated. CGE modelers point out the lack of information relating to TF implementation programs at the global level, with no mechanism to model these costs within the CGE framework. The majority of TF related GTAP models assume that TF can be achieved at no cost. There is a lack of investigations of governmental budget constraints in implementing TF measures in the GTAP applications. However, this may require large investment needs and government spending, particularly in developing countries. This must be a priority in future research as cost-benefit assessment is integral to determining the net global benefits of TF.

\section{References}

[1] Otsuki, T., Honda, K. and Wilson, J. (2013) Policy Review-Trade Facilitation in South Asia. South Asian Journal of Global Business Research, 2, 172-190. https://doi.org/10.1108/SAJGBR-12-2011-0052

[2] Hummels, D., Minor, P., Reisman, M. and Endean, E. (2007) Calculating Tariff Equivalents for Time in Trade. United States Agency for International Development (USAID).

[3] Hummels, D. (2000) Time as a Trade Barrier. Purdue CIBER Working Papers, Paper 7, Purdue University.

[4] Minor, P. and Tsigas, M. (2008) Impacts of Better Trade Facilitation in Developing Countries. 11 th Annual GTAP Conference, Helsinki, Finland, 12-14 June 2008.

[5] Fox, A.K., Francois, J.F. and Londono-Kent, P. (2003) Measuring Border Crossing Costs and Their Impact on Trade Flows: The United States-Mexican Trucking Case. GTAP Working Paper, 1282.

[6] Dennis, A. (2006) The Impact of Regional Trade Agreements and Trade Facilitation in the Middle East and North Africa Region. World Bank Policy Research Working Paper, The World Bank, Washington.

[7] OECD (2003) Quantitative Assessment of the Benefits of Trade Facilitation. OECD Working Paper TD/TC/WP(2003)31/FINAL, Organization for Economic Co-Operation and Development.

[8] Shepherd, B. (2010) Facilitating Services Trade in the Asia-Pacific. ARTNeT Policy Brief.

[9] Persson, M. (2007) Trade Facilitation and the eU-aCP Economic Partnership Agreements: Who Has the Most to Gain? 10th Annual Conference on Global Economic Analysis, Purdue University, 24 April 2007.

[10] Djankov, S., Freund, C. and Pham, C. (2006) Trading on Time. World Bank Policy Research Working Paper.

[11] Walmsley, T. and Minor, P. (2015) Willingness to Pay in CGE Models. Impact ECON Working Paper No. 04. Impact ECON, Boulder.

[12] Decreux, Y. and Fontagne, L. (2011) Economic Impact of Potential Outcome of the DDA. CEPII Working Paper No. 2011-23. https://doi.org/10.2139/ssrn.2004831

[13] Zaki, C. (2014) An Empirical Assessment of the Trade Facilitation Initiative: Econometric Evidence and Global Economic Effects. World Trade Review, 13, 103-130. https://doi.org/10.1017/S1474745613000256

[14] Hildegunn, K., Pinali, N.E. and Geloso, M. (2006) Logistic and Time as a Trade 
Barries. OECD Trade Policy Working Paper, OECD.

[15] Hummels, D. and Schaur, G. (2013) Time as a Trade Barrier. The American Economic Review, 103, 2935-2959. https://doi.org/10.1257/aer.103.7.2935

[16] Hertel, T., Walmsley, T. and Itakura, K. (2001) Dynamic Effects of the "New Age" Free Trade Agreement between Japan and Singapore. Journal of Economic Integration, 446-484.

[17] Hoekman, B. and Konan, D.E. (1999) Deep Integration, Nondiscrimination, and Euro-Mediterranean Free Trade. World Bank Policy Research Working Paper 2130. https://doi.org/10.1596/1813-9450-2130

[18] Minor, P. and Hummels, D. (2013) Time as a Barrier to Trade: A GTAP Database of Ad Valorem Trade Time Costs. ImpactEcon, 2nd Edition. http://mygtap.Org/resources

[19] Limao, N. and Venables, A.J. (2001) Infrastructure, Geographical Disadvantage, Transport Costs, and Trade. The World Bank Economic Review, 15, 451-479. https://doi.org/10.1093/wber/15.3.451

[20] Brun, J.-F., Carrère, C., Guillaumont, P. and De Melo, J. (2005) Has Distance Died? Evidence from a Panel Gravity Model. The World Bank Economic Review, 19, 99120. https://doi.org/10.1093/wber/lhi004

[21] Nordas, H.K. and Piermartini, R. (2004) Infrastructure and Trade. Staff Working Paper, World Trade Organization.

[22] Portugal-Perez, A. and Wilson, J. (2012) Export Performance and Trade Facilitation Reform: Hard and Soft Infrastructure. World Development, 40, 1295-1307. https://doi.org/10.1016/j.worlddev.2011.12.002

[23] Francois, J. and Manchin, M. (2013) Institutions, Infrastructure, and Trade. World Development, 46, 165-175. https://doi.org/10.1016/j.worlddev.2013.02.009

[24] Behar, A., Nelson, B.D. and Manners, P. (2009) Exports and Logistics. Discussion Paper Series: Department of Economics, University of Oxford, Oxford.

[25] Fink, C., Mattoo, A. and Neagu, C. (2002) Assessing the Impact of Communication Costs on International Trade. World Bank Policy Research Working Paper 2929. https://doi.org/10.1596/1813-9450-2929

\section{Scientific Research Publishing}

Submit or recommend next manuscript to SCIRP and we will provide best service for you:

Accepting pre-submission inquiries through Email, Facebook, LinkedIn, Twitter, etc. A wide selection of journals (inclusive of 9 subjects, more than 200 journals)

Providing 24-hour high-quality service

User-friendly online submission system

Fair and swift peer-review system

Efficient typesetting and proofreading procedure

Display of the result of downloads and visits, as well as the number of cited articles

Maximum dissemination of your research work

Submit your manuscript at: http://papersubmission.scirp.org/

Or contact tel@scirp.org 